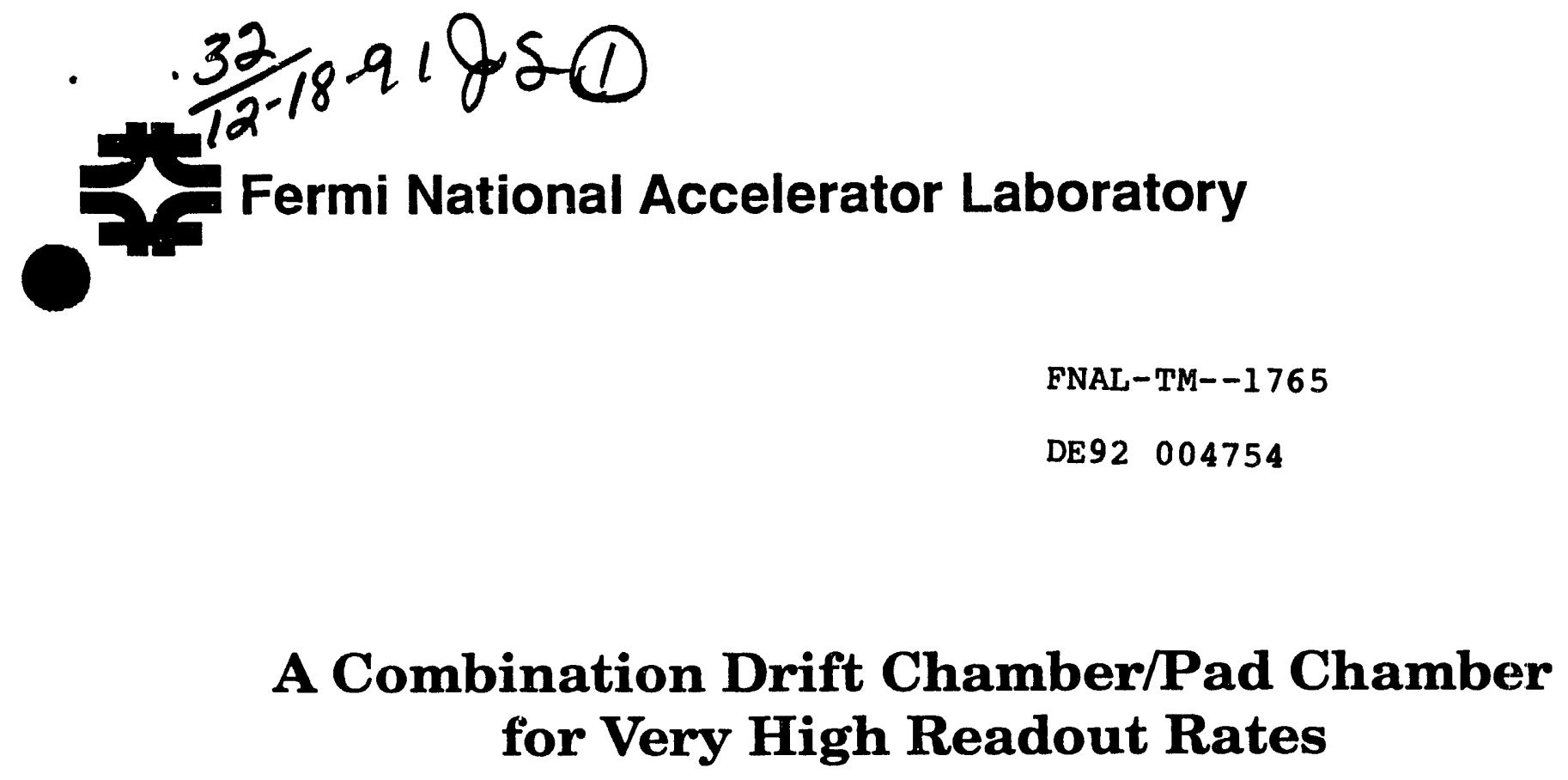

L. Spiegel ${ }^{5}$, T. Alexopoulos ${ }^{17}$, L. Antoniazzi ${ }^{11}$, M. Arenton ${ }^{16}$, C. Ballagh ${ }^{1}, \mathrm{H}$. Bingham ${ }^{1}$, A. Blankman ${ }^{13}$, M. Block ${ }^{10}$, A. Boden ${ }^{2}$, S. Borodin ${ }^{13}$, J. Budagov ${ }^{3}$, Z.L. Cao ${ }^{15}$, G. Cataldi' T.Y. Chen ${ }^{9}$, K. Clark ${ }^{14}$, D. Cline ${ }^{2}$, S. Conetti ${ }^{16}$, M. Cooper ${ }^{18}$, G. Corti ${ }^{10}$, B. Cox ${ }^{16}$, P. Creti ${ }^{7}$, E. Dukes ${ }^{16}$, C. Durandet ${ }^{17}$, V. Elia ${ }^{5}$, A. Erwin ${ }^{17}$, L. Fortney', V. Golovatyuk ${ }^{16}$, E. Gorini ${ }^{7}$, F. Grancagnolo ${ }^{7}$, M. Haire ${ }^{12}$, P. Hanlet ${ }^{16}$, M. He ${ }^{15}$, G. Introzzi ${ }^{11}$, M. Jenkins ${ }^{14}$, J. Jennings ${ }^{17}$, D. Judd ${ }^{12}$, T. Kaeding ${ }^{1}$, W. Kononenko ${ }^{13}$, W. Kowald ${ }^{4}$, A. Lanza ${ }^{11}$, K. Lau ${ }^{6}$, T. LeCompte ${ }^{10}$, G. Liguori' ${ }^{11}$, J. Lys ${ }^{1}$, P. Mazur ${ }^{5}$, A. McManus ${ }^{16}$, S. Misawa ${ }^{1}$, G. Mo ${ }^{6}$, C.T. Murphy' ${ }^{5}$ K. Nelson ${ }^{16}$, M. Newcomer ${ }^{13}$, M. Panareo ${ }^{7}$, S. Ramachandran ${ }^{2}$, M. Recagni ${ }^{16}$, J. Rhoades ${ }^{2}$, J. Rosen ${ }^{10}$, J. Segal ${ }^{16}$, W. Selove ${ }^{13}$, R.P. Smith ${ }^{5}$, J. Sun ${ }^{16}$, S. Tokar ${ }^{2}$, P. Torre ${ }^{11}$, J. Trischuk ${ }^{8}$, T. Trojak ${ }^{13}$,

E. Tsyganov ${ }^{3}$, L. Turnbull ${ }^{12}$, R. VanBerg ${ }^{13}$, D. Wagoner ${ }^{12}$, C. Wang ${ }^{15}$, C. Wei ${ }^{15}$, W. Yang ${ }^{5}$, N. ' ${ }^{\prime}{ }^{9}$, T. Yao ${ }^{10}$, N. Zhang ${ }^{15}$, S.N. Zhang ${ }^{13}$ and B. Zou ${ }^{4}$

${ }^{1}$ University of California at Berkeley, ${ }^{2}$ University of California at Los Angeles, ${ }^{3}$ JINR, Dubna, USSR, ${ }^{4}$ Duke University, ${ }^{5}$ Fermilab, ${ }^{16}$ University of Houston, ${ }^{7}$ University of Lecce and INFN, Italy, ${ }^{8}$ McGill University, Canada, ${ }^{9}$ Nanjing

University, P.R. China, ${ }^{10}$ Northwestern University, "University of Pavia and INFN, Italy, ${ }^{12}$ Prairie View A\&M

University, ${ }^{13}$ University of Pennsylvania, ${ }^{14}$ University of South Alabama, ${ }^{15}$ Shandong University, P.R. of China, ${ }^{16}$ University of Virginia, ${ }^{17}$ University of Wisconsin, ${ }^{18}$ Vanier College, Canada

November 1991 


\section{Disclaimer}

This "oport was prepared as an account of work sponsored by an agency of the United States Government. Neither the United States Government nor any agency thereof, nor any of their employees, makes any warranty, express or implied, or assumes any legal liability or responsibility for the accuracy, completeness, or usefullness of any information, apparatus, product, or process disclosed, or represents that its use would not infringe privately owned rights. Reference herein to any specific commercial product, process, or service by trade name, trademark, manufacturer, or otherwise, does not necessarily constitute or imply its endorsement, recommendation, or favoring by the United States Government or any agency thereof. The views and opinions of authors expressed herein do not necessarily state or reflect thase of the United States Government or any agency thereof. 


\title{
A Combination Drift Chamber'Pad Chamber for Very High Readout Rates
}

\begin{abstract}
L. Spiegel ${ }^{5}$, T. Alexopoulos ${ }^{17}$, L. Antoniazzi ${ }^{11}$, M. Arenton ${ }^{16}$, C. Ballagh ${ }^{1}$, H. Bingham ${ }^{1}$, A. Blankman ${ }^{13}$, M. Block ${ }^{10}$, A. Boden ${ }^{2}$, S. Borodin ${ }^{13}$, J. Budagov ${ }^{3}$, Z.L. Cao ${ }^{15}$, G. Cataldi ${ }^{5}$, T.Y. Chen ${ }^{9}$, K. Clark ${ }^{14}$, D. Cline ${ }^{2}$, S. Conetti ${ }^{16}$, M. Cooper ${ }^{18}$, G. Corti ${ }^{10}$, B. Cox ${ }^{16}$, P. Creti ${ }^{7}$, E. Dukes ${ }^{16}$, C. Durandet ${ }^{17}$, V. Elia ${ }^{5}$, A. Erwin $^{17}$, L. Fortney ${ }^{4}$, V. Golovatyuk ${ }^{16}$, E. Gorini ${ }^{7}$, F. Grancagnolo ${ }^{7}$, M. Haire ${ }^{12}$, P. Hanlet ${ }^{16}, \mathrm{M} . \mathrm{He}^{15}$, G. Introzzi1 ${ }^{11}$, M. Jenkins ${ }^{14}$, J. Jennings ${ }^{17}$, D. Judd ${ }^{12}$, T. Kaeding ${ }^{1}$, W. Kononenko ${ }^{13}$, W. Kowald ${ }^{4}$, A. Lanza ${ }^{11}$, K. Lau ${ }^{6}$, T. LeCompte ${ }^{10}$, G. Liguori ${ }^{11}$, J. Lys ${ }^{1}$, P. Mazur ${ }^{5}$, A. McManus ${ }^{16}$, S. Misawa ${ }^{1}$, G. Mo $^{6}$, C.T. Murphy ${ }^{5}$, K. Nelson ${ }^{16}$, M. Newcomer ${ }^{13}$, M. Panareo ${ }^{7}$, S. Ramachandran ${ }^{2}$, M. Recagni ${ }^{16}$, J. Rhoades ${ }^{2}$, J. Rosen ${ }^{10}$, J. Segal ${ }^{16}$, W. Selove ${ }^{13}$, R.P. Smith ${ }^{5}$,

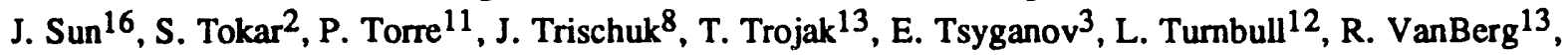
D. Wagoner ${ }^{12}$, C. Wang ${ }^{15}$, C. Wei ${ }^{15}$, W. Yang ${ }^{5}$, N. Yao 9 , T. Yao ${ }^{10}$, N. Zhang ${ }^{15}$, S.N. Z.ang ${ }^{13}$, B. Zou ${ }^{4}$

${ }^{1}$ University of California at Berkeley, ${ }^{2}$ University of California at Los Angeles, ${ }^{3} \mathrm{JINR}$, Dubna, USSR, ${ }^{4}$ Duke University, ${ }^{5}$ Fermilab, ${ }^{6}$ University of Houston, ${ }^{7}$ University of Lecce and INFN, Italy, ${ }^{8}$ McGill University, Canada, ${ }^{9}$ Nanjing University, P. R. China, ${ }^{10}$ Northwestern University, ${ }^{11}$ University of Pavia and INFN, Italy, ${ }^{12}$ Prairie View A\&M University, ${ }^{13}$ University of Pennsylvania, ${ }^{14}$ University of South Alabama, ${ }^{15}$ Shandong University, P. R. of China, ${ }^{16}$ University of Virginia, ${ }^{17}$ University of Wisconsin, ${ }^{18}$ Vanier College, Carada
\end{abstract}

\section{INTRODUCTION}

Six medium-sized $\left(-1 \times 2 \mathrm{~m}^{2}\right)$ drift chambers with pad and stripe readout have been constructed for and are presently operating in Fermi National Accelerator Laboratory experiment E-771[1]. Each chamber module actually represents a pair of identical planes: two sets of anode wires, two sets of stripes, and two sets of pads. The wire planes are read out separately and represent $X$ measurements in the coordinate system of the experiment. The twin stripe and pad planes are internally paired within the chamber modules; stripe signals represent $Y$ measurements and pad signals combination $X$ and $Y$ measurements. Signats which develope on the stripes and pads are mirror (but inverted) images of what is seen on the wires.

The basic idea of the chamber pair is shown in fig. 1. In addition to being used in the off-line pattern recognition, pad signals are also used as inputs to an on-line high transverse momentum ( $\mathrm{p}_{t}$ ) trigger processor[2].

While the techniques involved in the design and construction of the chambers are not novel, they may be of interest to experimenters contemplating very large area, high rate chambers for future spectrometers.

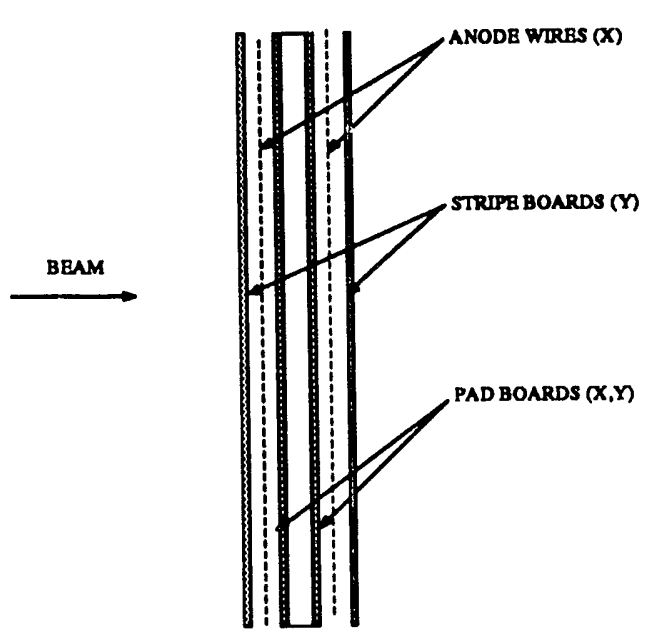

Fig. 1 Basic design of chamber pair

\section{DESIGN GOALS}

The pad chambers, as they are referred to, were designed for E-771 with the following criteria in mind:

1. To provide charged particle tracking coverage over $\pm 120 \mathrm{mr}$ in the horizontal plane and $\pm 60 \mathrm{mr}$ in the vertical plane, at stations approximately 8 and 13 meters following the production target. 
2. To provide pad signal inputs to an on-line programmable array logic trigger processor for the selection of high $\mathrm{pt}_{\mathrm{t}}$ muons.

3. To be capable of sustaining interaction rates as high as $10 \mathrm{MHz}$. There are several aspects to this requirement:

i. Minimizing both electron drift times and ion clear-out times.

ii. Holding the capacitance of the active elements, especially the larger pads, to a minimum so as to reduce signal decay times.

iii. Allowing for the passage of the beam and target fragments without activating (and thus overwhelming) the pre-amplifiers.

4. To allow for the disconnection or replacement of broken anode wires without the need to dismount the chamber.

There is one major drawback to the pad chambers, which should be noted: in the non-beam regions, each chamber module represents $7.2 \%$ of a radiation length and $1.7 \%$ of an interaction length, most of which is due to the stripe and pad boards. These numbers were judged to $L$ e acceptable by E-771, partly due to the fact that four of the six chambers are located at the rear of the tracking region and thus effectively blend in with the pre-convertor material of the electromagnetic calorimeter.

\section{CHAMBER NOMENCLATURE}

The six chambers are referred to as $\mathrm{CC} 1, \mathrm{CC} 2, \mathrm{CC} 3, \mathrm{CC} 4$, WC1, and WC2, where CC is meant to indicate a centrally located (with respect to the beam axis) chamber and WC a wing (off-axis) chamber. The central chambers all have passage holes for the non-interacting beam and target fragments. $\mathrm{CCl}$ and $\mathrm{CC} 2$ are identical chambers. Likewise $\mathrm{CC} 3$ and $\mathrm{CC} 4$ represent duplicates as do WC1 and WC2. The active area and bcam hole dimensions of the chambers are listed in Table I; Fig. 2 illustrates schematically the deployment of the chambers within the E-771 spectrometer.

Table I

Chamber Active Area Widths (cm)

\begin{tabular}{|c|c|c|c|c|}
\cline { 2 - 5 } \multicolumn{1}{c|}{} & $\Delta \mathrm{X}$ & $\Delta \mathrm{Y}$ & $\Delta$ Xhole & $\Delta$ Yhole \\
\hline $\mathrm{CC} 1(2)$ & 179.2 & 102.4 & 19.2 & 9.6 \\
\hline $\mathrm{CC} 3(4)$ & 115.2 & 179.2 & 19.2 & 16.8 \\
\hline $\mathrm{WC1}(2)$ & 115.2 & 179.2 & 0.0 & 0.0 \\
\hline
\end{tabular}
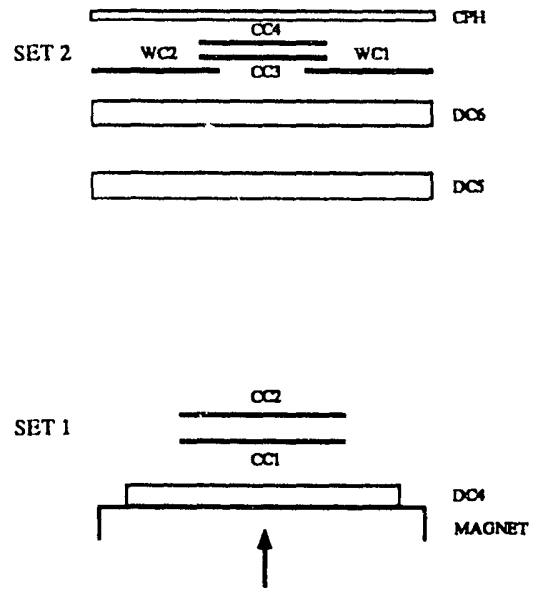

Fig. 2 Plan view of CC/WC deployment in E-771

From the viewpoint of the on-line trigger processor, $\mathrm{CC} 1$ and $\mathrm{CC} 2$ comprise one set of pad chambers while $\mathrm{CC} 3, \mathrm{CC} 4$, WC1, and WC2 comprise a second set. The processor uses pad signals from $\mathrm{CC} 2$ and pad signals from the combination of WC1, CC3, and WC2 to estimate the $p_{t}$ of tracks. CC1 serves as a backup for $\mathrm{CC} 2$ as does $\mathrm{CC} 4$ for $\mathrm{CC} 3$. All pad chamber signals are used in the off-line tracking.

In order to distinguish between the pairs of planes which make up a chamber module, the letter $A$ is used to designate the upstream set of wire, stripe, and pad planes, while B is used to designate the downstream set. Similarly it is sometimes necessary to distinguish between east and west (-X and $+X)$ sets of identical stripes within a given chamber. Finally, top and bottom refer to the $+Y$ and $-Y$ directions respectively.

Many of the chamber dimensions are quantized in units of $8.001 \mathrm{~mm}$ (0.315 in). For example, the drift cells are all exactly one unit square; pads are always one, two, or four units in width.

Table II is a summary of the number of wire, stripe, and pad elements in each chamber. There are 12,364 channcls in the entire system.

Table II

Channel Count

\begin{tabular}{|c|c|c|c|}
\cline { 2 - 4 } \multicolumn{1}{c|}{} & Wires & Stripes & Pads \\
\hline $\operatorname{CC} 1(2)$ & 448 & 320 & 2048 \\
\hline $\operatorname{CC} 3(4)$ & 288 & 330 & 163.2 \\
\hline WC1(2) & 288 & 288 & 540 \\
\hline
\end{tabular}

\section{ANODE WIRES}

Gold-plated tungsten wire, 50 microns in diameter, was selected for the chamber anodes. These wires are always surung 
vertically at a tension of 150 grams. The wire length is approximately $102 \mathrm{~cm}$ in set 1 and $179 \mathrm{~cm}$ in set 2 . For the second set, the wires are posted (glued) at the median plane to V-grooved FR 4 fiberglass spacers. This effectively halves the free length of the set 2 wires. No posting is done for set 1 wires with the exception of the beam hole region, where the wires are posted at both the top and the bottom of the hole. The V-grooves fill the cell and are approximately $1 / 8$ " wide along the wire direction.

Specially molded nylon inserts are used to position the wires. These inserts slip into rows of single-unit spaced holes which have been drilled in precision machined bars of cold rolled aluminum. In this manner the wires are centrally located within the drift cells. A picture of a typical wire bar with nylon inserts is shown in fig. 3.

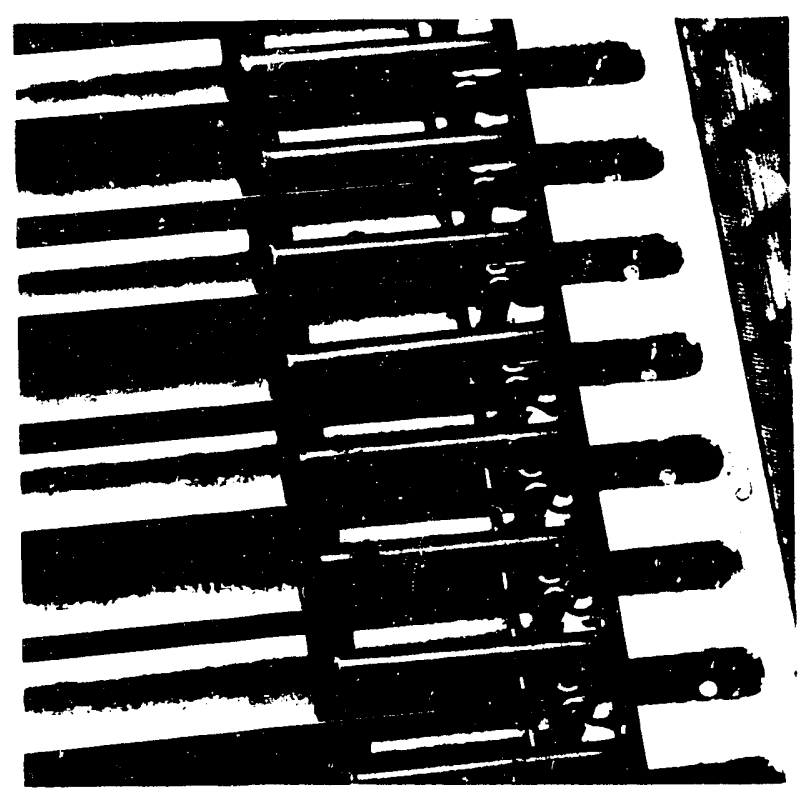

Fig. 3 Wire bar and nylon insert

After passing through the locating inserts, the wires are soldered to specially prepared printed circuit boards. Positive high voltage is supplied to the wires via the bottom board and through individual $1 \mathrm{M} \Omega, 1 / 2 \mathrm{~W}$ Alien-Bradley resistors. On the top printed circuit board, the wire signals are ac-coupled via $47 \mathrm{pF}, 6 \mathrm{kV}$ blocking capacitors into 16-channel surface mount connectors (3M 4634-2200). Short sections of iwisted-pair ribbon cables are used to go from these connectors to the preamplifier connectors (3M 3431-6205), which reside at the tops of the gas boxes.

Anode wires are partitioned by .002" x .187" full hard stainless steel foils which run parallel to the wires and perpendicular to the pad and stripe boards. These foils were tensioned by springs (Associated Spring Barnes Group 120018-250) which secured and grounded them to the top and bottom wire bars. The springs were tensioned to about $500 \mathrm{gm}$ so as to hold the foils straight. Like the wires, the foils adhere to the central and beam hole V-groove spacers. Unlike the wires, the foils do not pass through the beam holes. The purpose of the foils is to complete the sides of the drift cells and to provide for some isolation between cells. Foil widths wider than .187" would run the risk of shorting out either the pads or the stripes.

Wire signals are amplified just outside of the gas volume box, discriminated in fastbus postamp comparitors[3], and directed to LaCroy 4291 10-bit TDC modules.

\section{STRIPE BOARDS}

A and B stripe boards complete the assembly of the drift cells. They are mounted to the assembly of wires and pad boards. Removal of stripe board A allows access to the Awires and A-pads.

Both the stripe boards and the pad boards were fashioned from the same stock of $1 / 16$ " double-sided copper-clad (1 $\mathrm{oz} / \mathrm{ft}^{2}$ ) FR-4 fiberglass board. In the case of the stripe boards, a special computer-controlled machine created the stripes by routing $1 / 16$ " horizontal lines in the copper cladding. Stripes were created in two basic widths: half-unit pitch for the central 32 stripes of the set 1 chambers and the central 64 stripes of the set 2 chambers, and full-unit pitch for the remainder of the stripes in both sets. The area spanned by the stripes matches the active area of the wires and pads.

At a selected end of the stripe boards the stripes were brought together in groups of 16 channels by routing out the footprint of a latch/ejector header (3M 3431 6203). The same computer- controlled machine as before drilled out a set of 17 pairs of holes (one pair is for ground) for the connectors, the mounting of which takes place on side away from the wires. A and B stripe connectors are shorted together by a common ground-mesh ribbon cable which connects to the gas box side panel pre-amplifier connectors (3M 3431-6205). For the wing chambers, the stripe connectors are on the side of the gas box which is away from the beamline; for $\mathrm{CC} 3$ and $\mathrm{CC} 4$ they are on the east side. $\mathrm{CCl}$ and $\mathrm{CC} 2$ each contain two sets of stripes: an east and a west pair. These sets were created by making a 1/8" wide vertical cut in the middie of the stripe boards.

The outer faces of the stripe boards are solid copper with the exception of the areas in which the connectors are mounted. All stripe bcards contain a perimeter of $3 / 4 "$ aluminum box beam which has been glued to them. These serve two purposes:

1. They rigidify the stripe boards and thus help to rigidify the chamber pair assembly.

2. The top and bottom box beams are used to distribute gas to each drift cell as described in section VII.

Stripe boards are located with respect to the wire and pad assembly by a set of four alignment pins which project through the comers of the entire assembly (stripe boards, wire bars, and pad boards). The stripe boards are physically secured to the wire/pad assembly by: 
1. Screw holes in the wire bars. This provides for electrical contact to the outer copper cladding.

2. A handful of nylon screws which attach to a set of FR -4 spacers mounted to the pad boards. The anode wires pass through these spacers and the nylon screws are sufficiently short so as to avoid contact with the wires.

Amplified signals from the OR'ed stripe chanizels are directed to the same fastbus system as described in section IV. Unlike the wire signals, the stripe signals are processed entirely within the fastbus system and are not time-digitized.

\section{PADS}

Pads are formed by routing out rectangular patterns from the same FR-4 fiberglass stock as described in section V. Pad sizes vary, increasing in area away from the beamline. The horizontal widths of the pads are of three basic types: one-unit, two-unit, and four-unit. Granularity becomes coarser away from the beam axis. Vertically, the pads have been divided into identical sets of ten upper and ten lower Y-bands, again with band height increasing away from beam center. Set 1 bands are respectively $3,3,4,4,4,4,6,11,11$, and 14 units tall. The heights in set 2 are exactly 1.75 times the heights in set 1 , providing a projectivity to the target. Within the three basic chamber designs there are 32 distinct pad sizes and these range in area from a minimum of $1.92 \mathrm{~cm}^{2}$ to a maximum of 112.0 $\mathrm{cm}^{2}$. A drawing of the pads of one quadrant of $\mathrm{CCl}$ (or $\mathrm{CC} 2$ ) is shown in fig. 4. The central chamber pads have a quadrant symmetry; the wing chamber pads have a top-bottom symmetry.

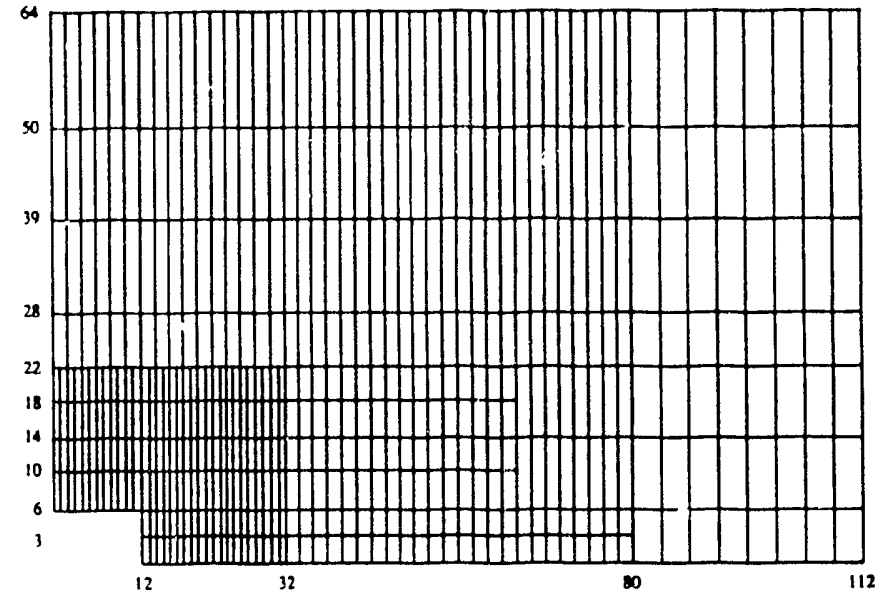

Fig. 4 CC1 pad quadrant

In order to minimize the pad-to-ground capacitance, the back sides of the pad planes have copper removed in the location of the larger pads. The removal process leaves a ground lattice which provides a nearby reference for the pad signal cable. Figures 5a and 5b show examples of the pad and ground sides of a pad hoard.

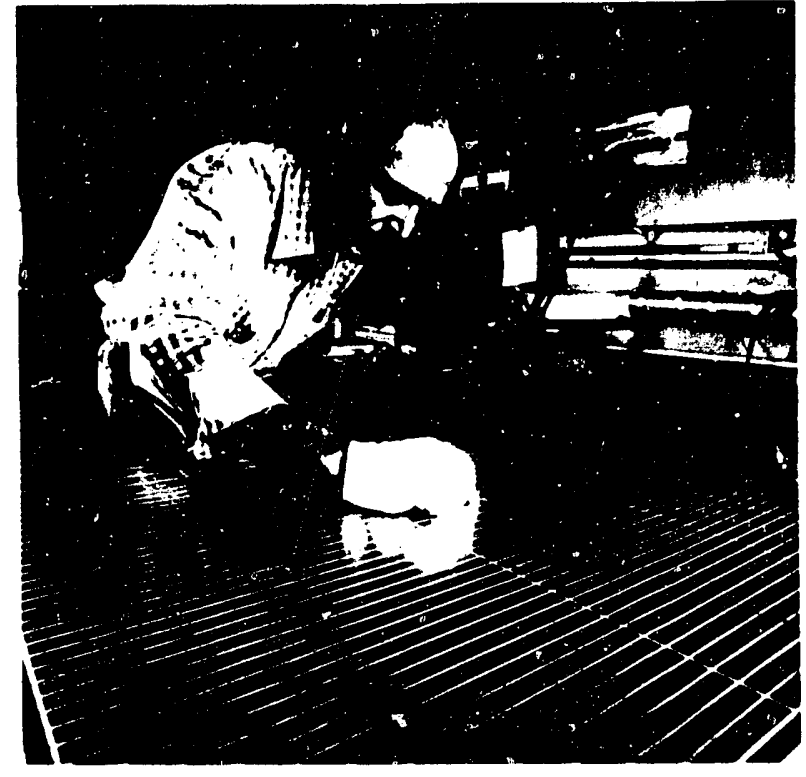

Fig. .ia Typical pad board

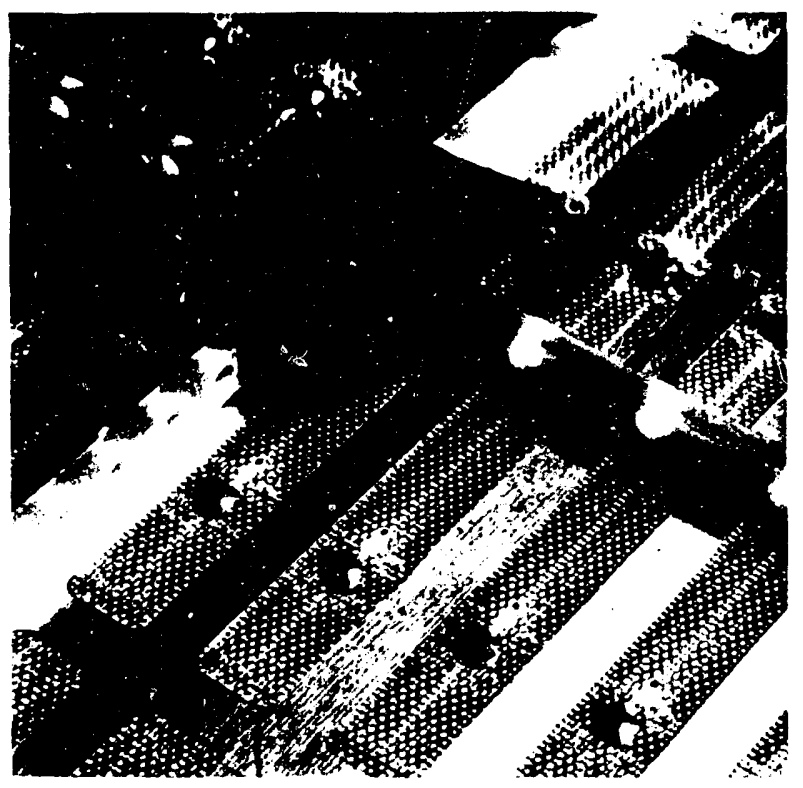

Fig. 5b Typical pad board reverse side

Corresponding $A$ and $B$ pads are shorted together by a system of bus wire which connects $A$ with $B$ and $A$ with an iniernal microcable (Alpha \#9475 0.065 diameter, $80 \Omega, 52.8$ $\mathrm{pF} / \mathrm{n}$ : coax cable). As plated holes were not feasible for the large pid boards, the bus wires are bent over into furrows and solder-bridged to the pads. Initially there was some concern that the solder mounds might lead to discharges; experience has shown this not to be the case.

The microcables were routed through an interlocking network of $0.245^{\prime \prime}$ FR-4 fiberglass spacers which contain passage holes for up to six cables (see fig. 5b). Once the routing of cables was complete for plane A, a pad laminate 
was constructed by epoxying together plane $A$, the spacer network, and plane $B$. This fairly rigid structure then became the backbone of the chamber pair system. The same system of alignment holes and dowel pins as described in section $\mathrm{V}$ registered the pad planes to the other planes.

Once the A and B pads have been bussed together, the wire bars are attached to the top and bottom of the laminate and additional aluminum bars are used to secure the sides. The wires and foils may then be attished at this point.

Pad microcables are mass-terminated in groups of sixteen channels at connectors (3M 3431-6203) which reside on either the gas box side plates (set 2) or the top and botto $m$ plates (set 1). The solder connections are then permanently frotted in place. Microcable lengths vary depending on the slistance needed to get from pad to connector. The longest length is about a meter.

Following amplification, pad signals are directed to the same fastbus system described in previous sections; they are recorded in the same manner as the stripe signals. Special auxiliary boards, located on the backside of the fastbus crates, distribute copies of the pad signals to the $\mathrm{p}_{\mathrm{t}}$ trigger processor.

\section{GAS BOXES}

Each chamber pair is encased in a 4 " thick rectangular box which is in turn suspended from an overhead I-beam mounted transverse to the beamline. The boxes serve three essential functions:

1. They provide a sealed environrnent for the operating gas of the chamber pair.

2. They support the chamber pair.

3. Their perimeter panels contain the feedthrough latch/ejector connectors as mentioned in the wire, stripe, and pad sections.

In keeping with the A-B symmetry of the chambers, each gas box contains both upstream and downstream detachable windows. These consist of $0.005 "$ mylar glued to a picture frame of $1 / 2$ " aluminum. Aluminum foils, 0.002" in thickness, have been affixed to the outer frames in order to limit noise pickup on the chamber elements and internal cables. The windows are bolted directly to the main box and in doing so compress a rubber gasket which insures a tight gas seal. The amount of material - aluminum foil and mylar amounts to $0.2 \%$ of a radiation length and $0.08 \%$ of an interaction length per $\mathrm{CC}$ chamber within the beam hole regions.

In addition to the signal connector feedthroughs, the gas boxes also contain high voltage and gas feedthroughs. High voltage is supplied separately to the $A$ and $B$ wire planes (with a further east-west division in $\mathrm{CC} 1$ and $\mathrm{CC} 2$ ). Chamber gas is taken in at the top of the boxes and directed to gas manifolds at the tops of the A and B stripe boards. These manifolds contain a row of single-unit spaced holes which direct the gas through individual drift cells. Another set of holes, near the bottom ends of the wires, discharges the gas into the box reservoir; an exhaust line at the base of the box sends the gas to an external bubbler.

\section{CHAMBER OPERATION}

In keeping with the rate requirements of the chambers, the pre-amplifiers have been designed around the assumption of operating in the semi-proportional mode. With the present operating gas of 50/50 Argon-Ethane bubbled through ethanol at $0^{\circ} \mathrm{C}$, the wires reach an efficiency plateau at $+2200 \mathrm{~V}$. Both the stripe and pad planes reach plateaus before the wire planes by about a hundred volts. TDC distributions from the wires show a time jitter of $100 \mathrm{~ns}$, which is about what one would expect given the $8 \mathrm{~mm}$ cells and use of Argon-Ethane.

At this point the six chambers have been in operation for about three months. For the most part their performance has been trouble-free. As more detailed resolution and efficiency studies are conducted and analyzed, it is anticipated that a more detailed report will be made concerning their performance.

\section{FABRICATION COSTS}

Approximately $\$ 20 \mathrm{~K}$ was spent per chamber in machine shop time and equipment. This does not include the use of Lab facilities such as the computer-controlled routers, which were not directly billed, nor does it include salaries. This figure is still considurably smailer than the cost of instrumenting a chamber.

\section{ACKNOWLEDGEMENTS}

The authors wish to acknowledge the support of the U.S. Departmeint of Energy for underwriting the costs of building the pad chambers and the support of the Fermi National Accelerator Labcratory for facilitating their construction. Fermilab is operated by Universities Research Association, Inc. under contract with the U. S. Department of Energy.

Over the course of time many employees of the Fermilab Physic: Department contributed toward the construction of the pad chambers. Special thanks go to D. Farnum, S. Harrold, P. Poll, and J. Schellpfeffer for design and drafting work; J. Bloomquist, P. Deering, J. Nelson, and C. Richard: on for the fabrication of the stripe and pad boards; and H. Bruch, $S$. Carlson, A. Lathrop, N. Michael, D. Quintero, and C. Serritella for the assembly of the chambers.

\section{REFERENCES}

[1] B. Cox et al., Fermilab Proposal E-771, April 1986.

[2] S.N. Zhang et al., "A High PT Muon Trigger Processor" to be published in the IEEE Conference Proceedings 1991.

[3] C. Swoboda et al., "A High-Rate Fastbus Silicon Strip Readout System", IEEE Transactions on Nuclear Science, Vol. 37, No 2, 1990. 

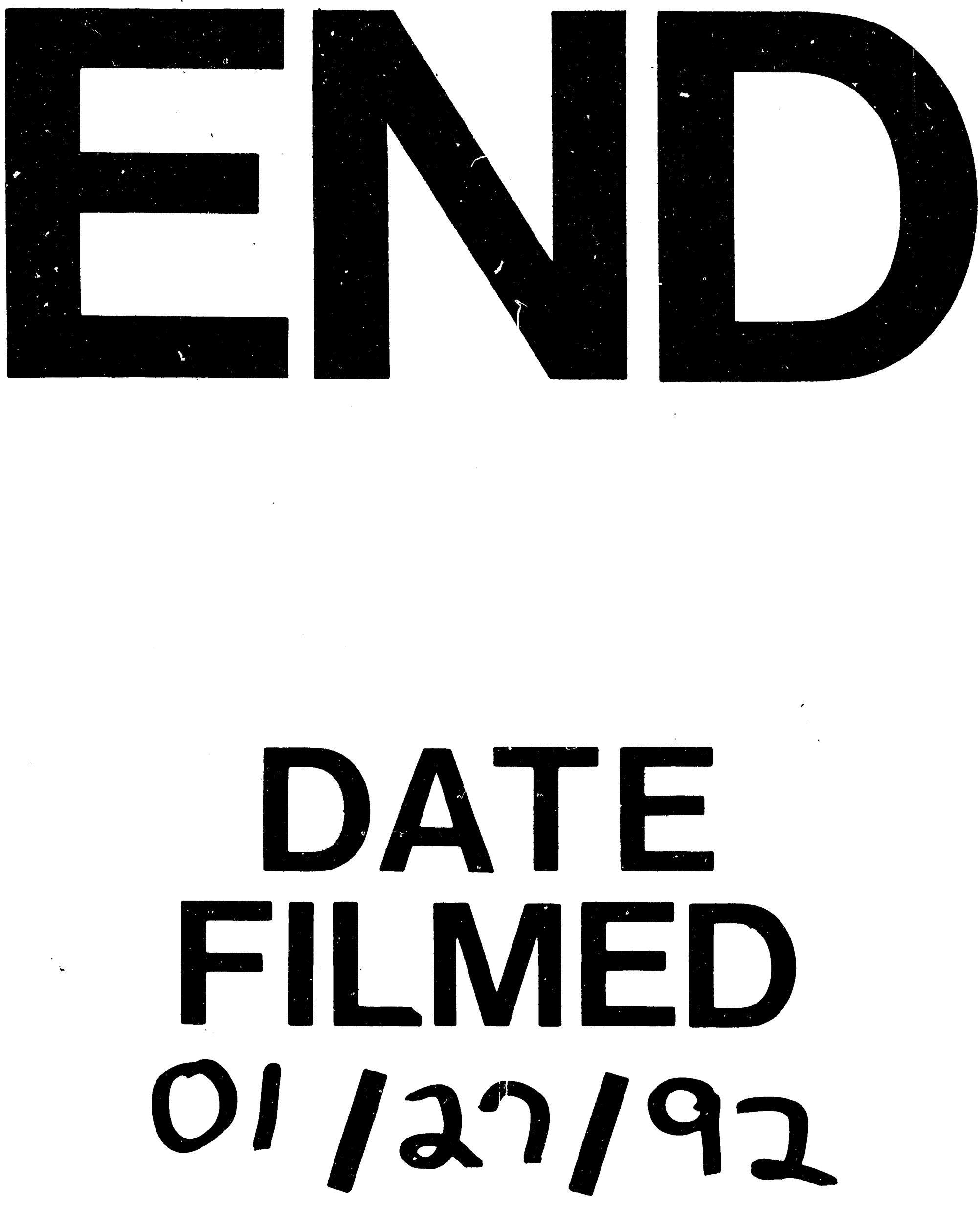

1 
